\title{
The Impact of the Development of Shale Gas on the Algerian Economy in the Presence of Uncertainties on Exports
}

\author{
Ouchene Amal \\ ouchene.amal@yahoo.fr \\ University of Boumerdes, Algeria
}

\begin{abstract}
For Algeria the energy has always been a convenience with a double importance: must ensure the energy security of the country on the very long term and be a main source for the financing of its economic and social development. Algeria meets the conditions for the shale gas production development and our country is already a major gas exporter, and local demand is now increasing to the point that conventional gas exports are likely to decline. Algeria relies heavily on gas export revenues $(90 \%$ of which come from hydrocarbon production). These additional gas reserves would therefore enable exports to continue to support the country's development. This paper aims the situation within the Algerian shale gas field to illustrate the various potential benefits and risks also. To better assess the situation and consider the best prospects, we will review the evolution of this sector in terms of energy supply and identify the challenges that must be overcome in order to ensure the country's energy security and guaranteethe financing of the economic and social development of the country, at least, throughout the transition to an economy independent of oil revenue.
\end{abstract}

Key words: shale gas, natural gas,environmental impacts, water consumption, strategy, risks, challenges.

\section{Introduction}

Algeria is among the top three countries of the world with proven shale gas reserves. The Algerian potential reserves are estimated at 707 TCF ( $9.3 \%$ of world total TRR), a reason why Algeria has intentions to enter the race to exploit its fields [1].

Secondly, Algeria is a long-time gas producer and has the infrastructure and technical expertise to support large-scale development across the sector. It has indeed a regional natural gas pipeline and several export pipelines, as well as an LNG terminal, showing the strength of its infrastructure for the domestic market or for export.

The question is whether the exploitation of this shale gas, through its economic spin-offs as well as its negative environmental externalities, can be a solution to overcome the current crisis and protect the national economy. The research gap of this paper highlights the Algerian position concerning the shale gas exploitation and also aims an analysis of the reasons towards illustrate the main constraints and also the expected benefits for the Algerian economy within the shale gas exploitation.

\section{Problem Statement}

Algeria is a major gas producer and exporter, but its fast growing domestic consumption shall lead to a decline in its exports; shale gas**7could then play an important role in its economy given the significant potential of shale gas reserves that will enable Algeria to maintain the same level of exports without slowing down the national growth.

The problematic is reflected in the answer to the following questions:

- Algeria consumes a third of its gas production, it will not remain enough by 2025. Would shale gas be the alternative?;

\footnotetext{
${ }^{*}$ Corresponding Author: Ouchene Amal

** "Shale gas" is references to "shale" called a rock with a laminated appearance which candecompose into fine plates.
} 
- which are the Algerian natural gas on the international market where significant changes, or even upheavals, are occurring and/or predictable in the short and medium term?

The essential basins are: Ghadames (Berkine), Illizi, Timimoun, Ahnet and Mouydir, Reggane and Tindouf [5].

If Algeria is moving towards the exploitation of these unconventional deposits, it will surely ensure, at

least for some decades, its internal needs and will as a preferred supplier for European and Asian countries. It could even increase the production and move towards new markets.

\section{Algerian gas industry statement}

Algeria is a state-member of the Organization of Petroleum Exporting Countries (OPEC) and is traditionally a large conventional natural gas producer in Africa.

In 2016, Algeria accounted for about $30 \%$ of natural gas reserves on the continent, $43 \%$ of production and 56 per cent of exports. Natural gas exports from Algeria represent almost $60 \%$ of national production, mostly to the European Union (more than $80 \%$ of LNG and pipeline exports).

The energy mix in Algeria is particularly reliant on fossil fuels, crude oil and natural gas, accounting for $99.6 \%$ of primary energy in 2016. Owing to the gradual depletion of ageing conventional deposits, Algeria has been increasing its interest in unconventional hydrocarbon resources, which are largely distributed in three main shale basins, namely Ghadames, Timimoun and Reggane, which hold 40,22 and 17 per cent, respectively, of total shale gas resources of Algeria.

First exploratory drilling test for shale gas was approved in 2014. However, it was suspended following large-scale protests from local populations. In October 2017, authorities considered the resuming unconventional operations by Sonatrach [5]. However, numerous barriers remain, such as the lack of adequate infrastructure, specific knowledge and skills, support services and equipment and machinery. The opposition of local populations to shale gas projects and security issues in the regions where the deposits are located may also continue to be substantial obstacles.

\subsection{Algerian gas reserves fields and production}

Gas fields represent one of the wealth of hydrocarbons that Algeria possesses with $56 \%$ of the total, oil 27\%, condensate $9 \%$ and LPG 7\% which there are among the world largest reserves.

According to Council of Ministers Report (October $\left.6^{\text {th }}, 2015\right)$, the Algerian proven reserves of natural gas were estimated at 2745 billion cubic meters [2].

The most important one is the HassiRmelfield but there is also the TFT, In Salah and Alrar to name only the most important ones.

The renewal of these reserves which is carried out through new discoveries and the revaluation of the reserves of certain existing fields, and/or through the use of new recovery techniques and through reinterpretation following the acquisition of new data, no longer covers the withdrawal. The country's reserves are declining from year to year. Renewal is currently estimated to be in the order of $30 \%$.

The ratio of reserves/production is estimated for the 21 years, situation that inevitably will leading to the outright disappearance of existing reserves if the replacement of these reserves isn't assured.

The hydrocarbons sector has, for several years, initiated several actions to intensify the exploration effort, accelerate the development of pending discoveries and use other sources of energy, renewable and unconventional ones in particular [6].

This desire of the energy sector is not sufficiently translated on the ground, the effort of the exploration is practically supported by Sonatrach alone (the foreign investments in the upstream oil are almost non-existent, the national private investment is non-existent despite the opening made by the law), the development of new discoveries takes a lot of time and the implementation 
of the renewable energy program is far behind [5]. To all these elements is added a discouraging business climate.

The level of reserves has largely evolved in Algeria as shown in table 1 [6].

Table 1.Evolution of proven reserves $\left(\mathrm{Gm}^{3}\right)$ of Algeria

\begin{tabular}{|c|c|c|c|c|}
\hline Year & 1985 & 1998 & 2002 & 2015 \\
\hline Reserves & 3030 & 3690 & 4523 & 2745 \\
\hline
\end{tabular}

The substantial increase in gas production [4] at the expense of the crudeis explained by the energy policy aiming at preserving liquid hydrocarbons but also by the increase of Algerian exports to Europe (table 2).

Table 2.Evolution of commercialized production of natural gas $\left(\mathrm{Gm}^{3}\right)$

\begin{tabular}{|c|l|l|l|l|l|l|l|l|l|l|l|}
\hline Year & 2006 & 2007 & 2008 & 2009 & 2010 & 2011 & 2012 & 2013 & 2014 & 2015 & 2016 \\
\hline Production & 84,5 & 84,8 & 85,8 & 79,6 & 80,4 & 82,7 & 81,5 & 82,4 & 83,3 & 84,6 & 91,3 \\
\hline
\end{tabular}

\subsection{Natural gas export}

Algeria's natural gas exports have gradually declined during the past decade as gross production decreased and domestic consumption increased, but 2016 saw a reversal of this trend. Algeria is facing pressure to boost natural gas output with new projects to meet growing domestic demand and to fulfill long-term contractual obligations to export natural gas to Europe.

Algeria became the world's first LNG producer in 1964 when the Arzew LNG facility came online [4] and has four liquefaction units for liquefied natural gas (LNG) located along the Mediterranean Sea at Arzew and Skikda, although a number of the LNG facilities (table 3) have been decommissioned, lowering actual production capacity [3].

Table 3.LNG facilities in Algeria

\begin{tabular}{|c|c|c|}
\hline Project Name & Number of Trains & Production Capacity $(\mathrm{Bcf} / \mathrm{y})\left(^{8}\right)$ \\
\hline Arzew LNG & & 379 \\
\hline GL1Z & 6 & 394 \\
\hline GL2Z & 6 & 226 \\
\hline GL3Z & 1 & 43 \\
\hline GL4Z (Camel) & & 216 \\
\hline Skikda & 1 & $21 K$ \\
\hline $\begin{array}{c}\text { GL1K } \\
\text { Megatrain }\end{array}$ & & \\
\hline
\end{tabular}

\subsubsection{The role of Algeria within the European gas supply}

Algeria is a major gas supplier for Europe. Several European countries are supplied with gas from the HassiRmel field in southern Algeria, and the delivered quantities have been increasing since 1964, date of the first deliveries of liquefied natural gas from Arzew to Convey Island in the United Kingdom. Today, Algeria exports about $60 \mathrm{Gm}^{3} /$ year to Europe and contributes to $15 \%$ of its consumption and $30 \%$ of its imports.

Conversely, Europe represents more than $95 \%$ of Algerian exports of natural gas. That is to say that all the importance of this market lays in Algeria's gas future.

Algeria is ableto play an even more important role in European gas supply. There are several reasons for this: the abundance and high potential of increasing the available reserves, the existence of a large, diversified and easily extensive infrastructure at low marginal cost, and the

${ }^{8}$ Billion cubic feet per year is Bcf/y 
long experience of the national company Sonatrach, both in LNG technology and in intercontinental pipelines [5].

But Europe, in particular the European Union, must adopt a clear policy of encouraging and supporting natural gas imports and not unilaterally changing the rules of the game without taking economic constraints into account which is holding back the development of international gas exchanges because of the capital-intensive nature of the gas chain, which requires a specific transaction model, which is now being challenged by the liberalization of markets.

The European gas industry has undergone many changes over the last thirty years. But for Algeria, the major challenge remains the same: to transport under economic conditions, the natural resources of the Sahara to the European market.

Challenge raised: Algeria has completed the first phase of its gas export program and wonders about the opportunity of the secondphase, with the extension of its LNG export capacity and the construction of new gas pipelines directly linking Algeria to Spain and Italy.

Obviously, the closer the links between Algeria and Europe, the more the European Union will take into account the specificities of the gas chain, and the more Algeria will consider with confidence, the increase of its gas exports to Europe.

\section{Discussions}

Algeria consumes one third of its gas production, it will not remain enough by 2025. Would Shale gas be the alternative?

It is rather the share of production to be exported which is likely to decrease starting from 2025, and consequently the income that makes our economy work if there is no renewal of our hydrocarbon reserves. This renewal cannot be ensured in principle either by exploration (discovery of additional conventional volumes), or by improving recovery rates in the current fields, or at least by the progressive compensation of the growth rate of consumption through new renewable energy production capacities.

The supply of the domestic market is still the priority, so there will be a problem of incomebythattime, although in any way this problem is already relevant because of the decline of the barrel since 2014, i.e. an uncontrollable factor and very unpredictable at the moment.

On the other hand, it is by 2030 and beyond that the situation will be worrying if none of the three solutions will be achieved by then, which leads us to say that it is better to be cautious and prevent a fourth alternative which corresponds to the exploitation of shale gas.

The exploitation of shale gas is no longer a choice, but an obligation?

Regarding the possibilities of renewal by new discoveries, there is at the present stage of knowledge no certainty of conventional discoveries which volume would be able to compensate the annual withdrawal from the existing reserves.

Of course there is still potential in many areas and therefore hydrocarbons to discover yet, but it is more complex, smaller in volume, more expensive, and more difficult to exploit, with a weaker capacity of renewal and especially spread over a longer period of time.

Therefore, this will require a lot of investment in new exploitation technologies. On the other hand, for conventional natural gas, its average recovery rate is already 70 to $80 \%$ with little chance of exceeding the rates already known for the various existing fields. However, it is not only the main source of our energy consumption, but will also tend to correspond to most of our hydrocarbon production and exports.

What about Algerian natural gas in an international market where major changes or even upheavals are ongoing and / or predictable in the short and medium term?

Many remind us that Algeria, rich in oil and gas, makes a substantial contribution to Europe's energy supply. More than 50 years ago, precisely in 1964, this country started to supply gas and since then, this flow has never been interrupted, highlighting, in passing, the reliability of this supplier.

The fact remains that for natural gas; Algeria faces many important constraints, and this, in several areas in particular, regarding: 
- Reserves, which level could be much lower than the level officially announced;

- Production, decreasing during the last years for various reasons;

- Development costs, highly increasing;

- National demand, in very high growth;

- Energy price policy in the domestic market, the leastwe can say, inappropriate;

- International commercial strategy, a priori inadequate, especially in a context that is witnessing on one hand falling prices and on the other hand, irreversible changes in demand and supply and regulation and organization.

In terms of conventional gas reserves, Algeria was the tenth largest in the world at the end of 2014, with OPEC accounting for 4,500 billion cubic meters $\left(\mathrm{Bm}^{3}\right)$. But this official figure, very recently revised downward, has remained unchanged since 2005, and several experts estimate that the remaining conventional gas reserves would be much lower, of the order of 2,000 $\mathrm{Bm}^{3}$. This level is corroborated by studies by Wood Mackenzie, which set recoverable gas reserves at 2,051 $\mathrm{Bm}^{3}$ as of January $1^{\text {st }} 2012$.

Certainly, discoveries have been made over the past three years, corresponding, on the basis of parsimonious information, to additional reserves of 200 to $500 \mathrm{Bm} 3$.

As for the commercialized production of natural gas, it has been declining during the past years, affected by technical problems and a decrease in the number of European customers' kidnappings.

Projections, based on existing capacity and which only take into account existing fields at the end of 2012, show that potential production in 2019 would be around $100 \mathrm{Bm} 3$, before starting to decline after 2020.

Annual production, for the entire 2012-2022 decade, would therefore, at best, be broadly maintained.

The other constraint, which isn't the least but about which we do not talk much, is the development costs. If the cost of producing the well output gas would currently be $\$$ 0.47/MMBtu on a weighted average basis, it should, still on a weighted average, almost double, with $\$ 0.80 /$ MMBtu starting from 2017 (fig.1). The production cost of new fields would be close to $\$ 2 / \mathrm{MMBtu}$. So, the production cost almost double? (fi

Figure 1.Weighted average into natural gas production area

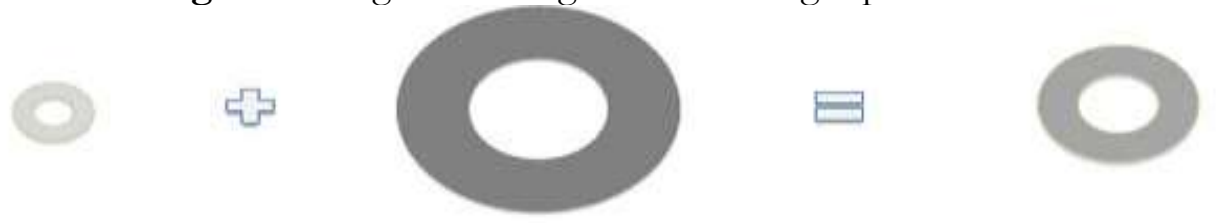

\begin{tabular}{|ccc|}
\hline Fields in production (2013) & Fields in development (2013-2017) & Weighted average (2017) \\
$0,47 \$$ MMBtu & $1,87 \$ / M M B t u$ & 0,80 \$/MMBtu \\
\hline
\end{tabular}

The effect for Algerian economy, does mean that the gas income should decrease significantly. The domestic market demand has been steadily increasing during the last years and reached nearly $40 \mathrm{Bm}^{3}$ (2014) and should continue to grow very strongly according to the Algerian Commission for Regulating Electricity and Gas (CREG). 
Figure 2.Limited exports up to $50 \mathrm{BCM} / \mathrm{y}$

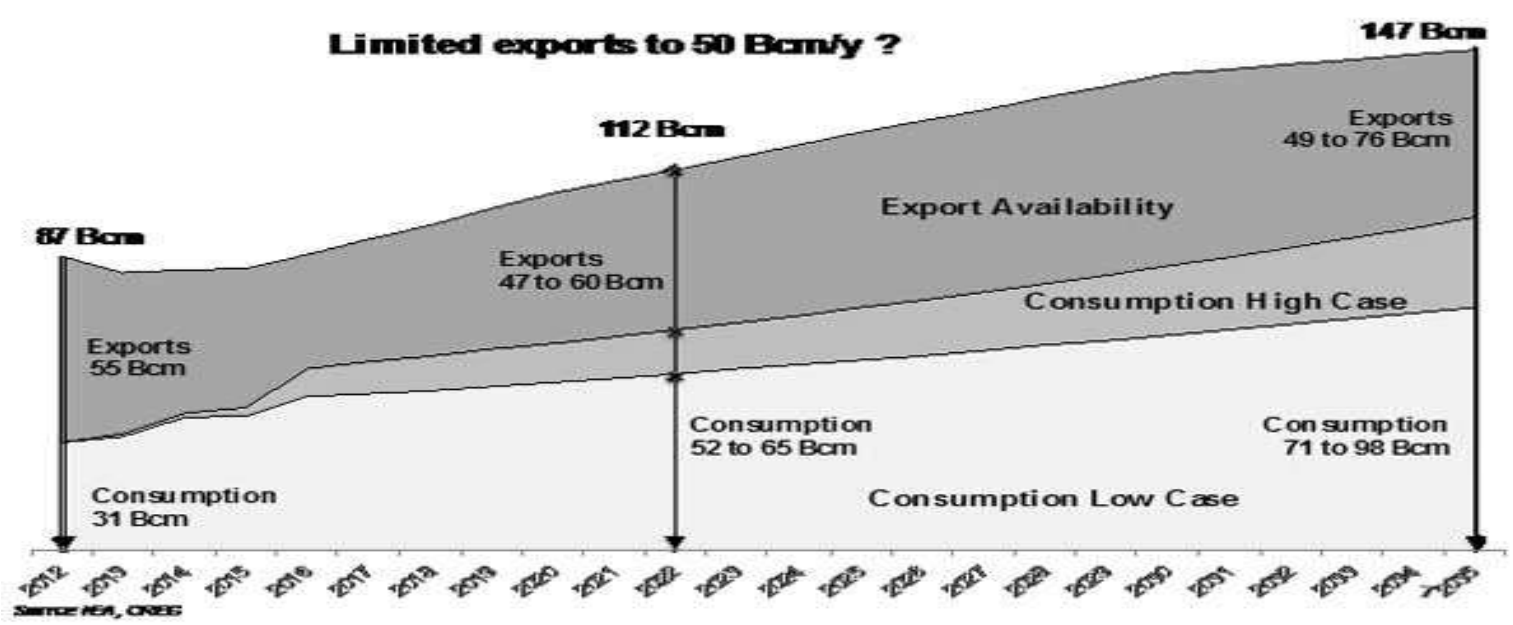

There is no doubt that these consumption levels will have a direct impact on the availability of natural gas for export (fig.2).

According to IEA, exports would hardly exceed $60 \mathrm{Bm} 3$ in 2022. With a high scenario of domestic demand, they would even be less than $50 \mathrm{Bm} 3$ [4].

This is to say the importance of the measures to be taken on the local market to hope to quickly reverse the consumption trend.

In Algeria, subsidies for energy products are important and very expensive. As a result, in 2014, the sale price of natural gas to the electricity and domestic sectors was only $\$ 0.44$ / MMBtu (one of the lowest in the world). It is $\$ 0.91 / \mathrm{MMB}$ tu for the industrial sector.

We are far from the export valuation, of $11-12 \$ / M M B t u$, or more, recorded in 2013-2014 or 67 \$ MMBtu currently.

If the purpose of these subsidies is to help the most disadvantaged households, they benefit more to medium and high income households and above all, they push for frenzy and waste.

The money spent on these subsidies could be invested in the sector with high potential for renewable energy.

On the international market, among all the changes that are occurring and that are not, or will not be, without impact on the marketing of Algerian gas, we will mention [7]:

(i) In Europe, gas consumption somewhat stagnant and prices more oriented downwards due to the economic situation, strong competition from other suppliers (Russia and Norway) who develop aggressive commercial positions and adapt to the new conditions and the restructuring of the market and finally, a strong development of spot references, in particular "hubs" NBP (UK) and TTF (Netherlands);

(ii) In Asia, where supply is mainly provided by LNG, a free fall in prices indexed to oil prices and a strong expected increase in supply, particularly from Austral, Russia and even the United States;

(iii) In the United States of America precisely, where shale gas production is very abundant, LNG exports, which should start by the end of 2015 - beginning of 2016 with definite repercussions in terms of availabilities and prices on the market,especially in Europe.

That is to say that Sonatrach will have to face very strong pressures, especially regarding the marketing of its LNG since, the two new liquefaction units (Skikda and Arzew) with a total capacity of more than $13 \mathrm{Bm}^{3} /$ year, designed at a time when prices were very high, were implemented on own funds and without being "backed" by long term contracts "take or pay". Indeed, the potentialities are huge.

They should enable Algeria, with significant efforts, to continue to play an important role in the international energy scene, especially in its relations with Europe.

Among these potentialities may will be mention:

- the importance of its mining field and its potential for conventional gas reserves, 
- the important infrastructures, both of production and transport, already existing and which could be increased at lower cost,

- the huge announced reserves of shale gas,

- the proximity of European markets,

- the huge solar energy reservoir,

- the partnership, especially if it were to be more balanced, etc.

Algeria has a very important mining area, insufficiently explored, with just fourteen boreholes per $10,000 \mathrm{~km}^{2}$.

Significant investments have already been made on one hand, to intensify exploration efforts both on its

own and in association, in order to renew the reserves, and on the other hand, to increase the production of existing fields, by developing recovery capacities (secondary and tertiary) of hydrocarbons.

Algeria has also decided to embark on the exploration of unconventional gas, which, according to many experts, has a very high potential of 4 to 10 times the current level of conventional gas reserves. At the end of September 2015, the American EIA estimated that Algeria's shale gas reserves would be in the order of $20,000 \mathrm{Bm}^{3}$, ranked $3 \mathrm{rd}$ of the world, behind China and Argentina and just ahead of the United States [7].

However, the non-availability of water resources (excluding groundwater) in the Sahara area is a major constraint for hydraulic fracturing, the only technique proven to date, for the production of unconventional gas. The environmental impact is also a major obstaclethat the authorities must take into consideration [7]. Algeria could therefore maintain, at the very least, its current levels of production in order to meet its rapidly growing national needs, as well as its export commitments (fig. 3)[7].

Figure 3.U.S. Energy Information Administration World (IEA) Production into the Algerian fields

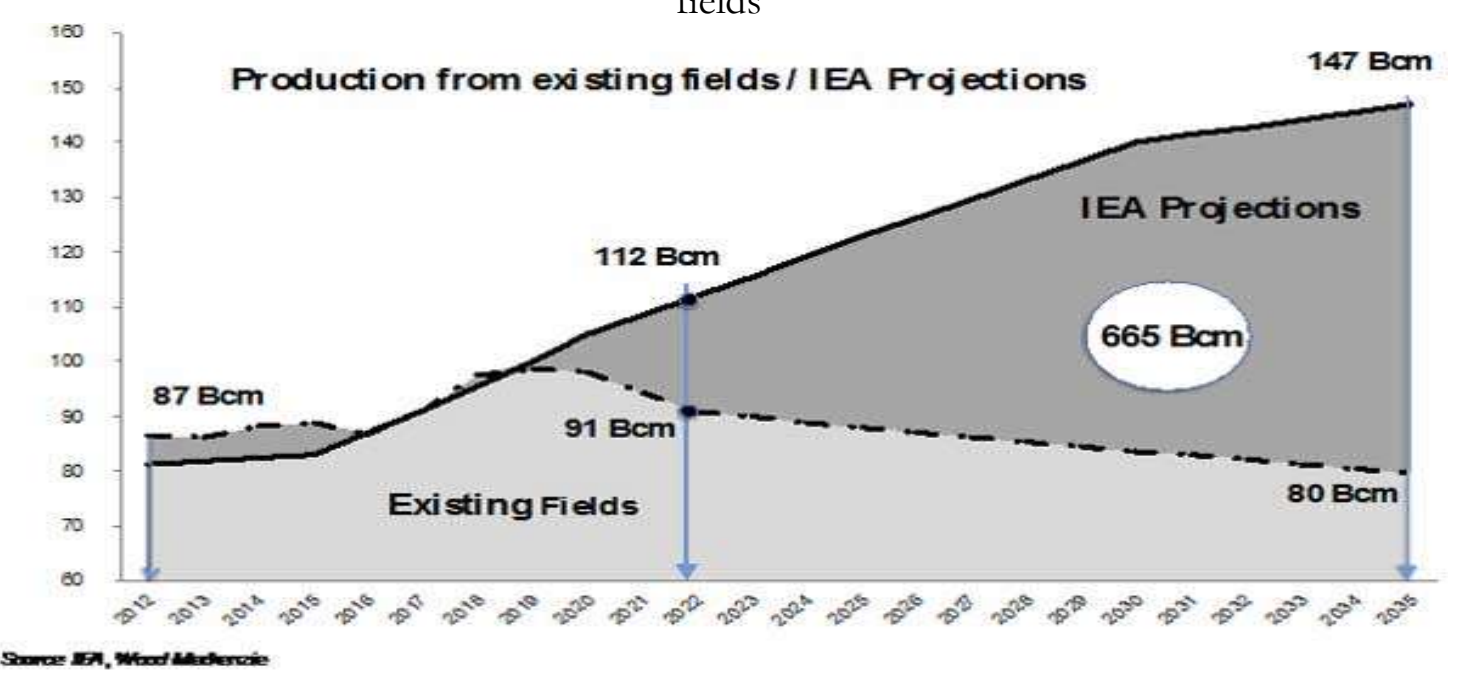

If production, from existing fields, remains close to an average of $90 \mathrm{Bm} 3$ / year by 2022 and would reach only $80 \mathrm{Bm}^{3} /$ year in 2035, the IEA forecasts show a strong growth in Algerian production until 2030, then a smaller increase between 2030 and 2035, reaching nearly $150 \mathrm{Bm} 3$ per year bythat time (figure above).

These forecasts include the discovery and development of new resources (recovery, conventional gas and shale gas), the first effects of which appear only as of 2019.

For 2022 year, the IEA predicts a production of $112 \mathrm{Bm}^{3}$ while existing fields are expected to produce only $91 \mathrm{Bm}^{3}$. 
Over the years between 2019 - 2035, two production forecasts show a cumulative difference of $665 \mathrm{Bm}^{3}$ and this gap is well below the conventional gas potential and the improvement of the recovery without counting, shale gas reserve estimates [4].

But such a level of production can only be achieved if a true partnership is developed with foreign companies. The results of the last $\mathrm{E} \& \mathrm{P}$ tender offers showed a rather weak attraction of the new law on hydrocarbons.

In addition to this production potential, Algeria has significant natural gas processing and transmission capacities, both for the domestic market and for export.

With regard to LNG, the export capacity currently exceeds $35 \mathrm{Bm} 3$ / year, but starting from 2020 , it should start to decline gradually with the closure of liquefaction units, renovated in the early 1990s.

Gas pipelines are the main way of exporting Algerian gas with an existing capacity approaching $54 \mathrm{Bm}^{3} /$ year. capacity that could be increased at lower cost, especially for the two gas pipelines that reach Spain, with $+4 \mathrm{Bm}^{3} /$ year on the Maghreb Europe pipeline and $+8 \mathrm{Bm}^{3} /$ year on the Medgaz.

The potential export to Europe through these fixed links (in the West and the East also) is thus $66 \mathrm{Bm}^{3 /}$

year to which would be added the liquefaction capacity, i.e. a total of about $100 \mathrm{Bm}^{3} /$ year.

In this regard, our country can play a more important role in the international market, especially in Europe. Europe, which considers itself too dependent on the Russian supplier, is looking for greater security. In addition, with declining local production, this market will inevitably increase its imports, starting in 2020 [7].

Another potential, Algeria has one of the highest concentrations of solar energy in the world.

Its necessary and even vital for this country to invest heavily into renewable energies and human capital in order to anticipate the "after gas".

The establishment of such a high-value-added industry could be an important vector of growth, creating

jobs, gradually breaking out of the revenue and subcontracting model, and promoting intraregional

exchanges on the basis of complementarities.

In summary, the constraints are numerous and significant. The national context is far from being simple and the international energy situation is marked by major changes, which are accompanied by many uncertainties.

Oil and gas revenues continue to represent more than $95 \%$ of total export earnings.

This rentier economy entails a very high vulnerability to fluctuations in the price of oil. Nevertheless, very strong potential exists with great challenges.

In conclusion, for Algeria the objectives should be:

- rapidly optimize the exploitation of its existing fields, in order to reach and maintain, over a period of at least ten years, the level of 110-120 Bm3 of marketed production;

- strongly increase its reserves of gas to be able to meet, with medium (2025) and long (2035) terms, its needs, both national and export;

- reflection without delay and in a progressive and consequent way its national energy policy in particular, in the matter of price subsidies, economic realism obliges, and the saving of energy, in order to stop the current waste;

- create an advantage of revenues from hydrocarbons to develop, within five to ten years, a real know-how to move from the exploitation stage to that of the design and implementation of projects and thus, permanently get out of the rentier and subcontracting model;

- trade police revolving area to take into account the changes taking place on the international market; 
Indeed, instead of continuing to rely on a marketing model, which is no longer appropriate, it may be important to develop aggressive commercial positions as well as new marketing models. Revising a price formula and/or offering flexibility in line with market conditions will be, in the context of a long-term strategy, much more profitable than the loss of market shares, which are always difficult to recover.

- Highly develop, under a special plan, solar energy for the national electricity production, in order to reduce, as much as possible, the consumption of natural gas

- To consider and implement an approach based on cross-interest partnerships, within the framework of a global and long-term vision, without forgetting the opportunities of the future of the Mediterranean region;

- Establish a stable and long-term regulatory framework to ensure the overall development of the energy sector.

\section{Conclusion}

We will therefore produce more gas than oil in the coming decade, we will consume more gas during the transition period by 2035 , and it is very likely that gas will also be the main source of gasrevenue for the same period. The current level of conventional reserves will not be able to meet all these needs, hence another uncertainty beyond 2030-2035 for natural gas.

And on top of that, the growth rate of energy consumption (electricity and natural gas) is breaking records every year ( +5 to $8 \%$ on average) but it should be noted in addition that the low performance in energy saving, mainly because of its transfer price and its subsidy.

Shale gas is no longer a choice but an obligation. It should not be considered as a source of financial income that will have to be generated by other activities in the future, but as a source of energy that can take over from other sources, in an energy mix starting in 2030 to ensure Algeria's energy security and lessen the pressure on conventional reserves that will continue to play an important role in the Algerian economy well beyond 2040.

The latest UNCTAD Report on shale gas is an excellent and very relevant analysis, with reliable data overall, this analysis has "pinpointed" the errors and environmental nuisances that have been caused or likely to be caused, but it has resulted in many recommendations, mainly aiming at preventing and avoiding environmental errors and nuisances, thanks to the technological progress that has occurred and likely to occur in the future, and of course a strict regulation with means of control and monitoring of the non-conventional hydrocarbon activity [6].

\section{References}

1. Background reference: Algeria, available on line bttps:// www.eia.gov/beta/international/ analysis_includes/countries_long/_Algeria/background.btm

2. BP Statistical Review of World Energy Available on line; bttp:// wmw.bp.com/ en/global/ corporate/ energy-economics/statisticalreview-of-world-energy June 2017.

3. BMI Research, wmw. hydrocarbons-technology.com, GIIGNL 2017 Annual Report

4. EIA (U. S. Energy Information Administration). Technically recoverable shale oil and shale gas resources: an assessment of 137 shale formations in 41 countries outside the United States. Washington D. C. : EIA Publisher, June 2011 Available on line bttp:/ / www.madalenaenergy.com/downlod/ARI\%EIA\%20Intl\%20Gas\%APR\%202011520select.pdf Sonatrach, 2017

5. United Nations Conference On Trade And Development (UNCTAD), Commodities at the glance Series, Special issue on shale gas, N.9, 2018 Available on bttps:/ / unctad.org/en/PublicationsLibrary/suc2017d10_en.pdf

6. U.S. Energy Information Administration World (IEA), Shale Resource Assessments in Algeria Available on bttps:// mwn.eia.gov/analysis/studies/worldshalegas/pdf/_Algeria_2013.pdf 